\title{
Design and study of seeding devices for small selection seeding machines
}

\author{
Vladimir Nemtinov $^{1, *}$, Nikolai Kryuchin ${ }^{2}$, Alexandr Kryuchin $^{2}$, and Yulia Nemtinova ${ }^{1,3}$ \\ ${ }^{1}$ Tambov State Technical University, 392000, Sovetskaya st., 106, Tambov, Russia \\ ${ }^{2}$ Samara State Agricultural Academy, 446442, Uchebnaya st., 2, Ust-Kinelskiy, Samara region, \\ Russia \\ ${ }^{3}$ Tambov State University named after G.R. Derzhavin, 392000, Internatsionalnaya st., 33, Tambov, \\ Russia
}

\begin{abstract}
In this paper, it is proposed to use a self-propelled pneumatic mini-seeder with replaceable mechanical sowing devices designed and manufactured using computer technologies, advanced software and threedimensional printing for seeds selection. As a result of the research, hightech operating devices for a grain-drill feed with screw and disk-pin continuous seed metering are designed and manufactured. Grain-drill feeds allow sowing of free-flowing and non-free-flowing seeds, when used as seed meters on self-propelled pneumatic mini-seeders for selection sowing of grass seeds. Analysis of laboratory results of and field studies of the proposed grain-drill feeds allowed to determine the qualitative indicators of their performance: at a disk rotation speed of up to $15 \mathrm{rpm}$ a linear dependence of the seed supply on the rotation frequency is provided; in the field studies, the instability of bluegrass seeding did not exceed $8 \%$. The highest performance of the screw is obtained at the angle of choke inclination of $30 . .35$ degrees with the seeding instability indicator of $2.5 \ldots 3.5 \%$. The developed grain-drill feed will significantly reduce the range of seeders and expand the set of sown seeds of various agricultural plants with one brand of a grain-drill feed.
\end{abstract}

\section{Introduction}

The basis of food security of the state and provision of the population with quality food is development of the agricultural sector of the economy. Among important resource factors that determine effectiveness of crop production the leading role belongs to new perspective varieties of crops.

The specifics of mechanization of crop cultivation in seeds selection is the small size of land plots at all stages of selection and primary seed production, requirement of high accuracy of seed distribution, importance and uniqueness of the entire crop, ensuring the absence of macro- and micro-damage to seeds. In addition, it is required to use a large quantity of different types of machines, which are frequently applied only once at each

\footnotetext{
* Corresponding author: nemtinov@mail.gaps.tstu.ru
} 
stage of the selection. Therefore, it becomes tedious to create machines for mechanization of selection, testing and primary seed production.

Significant reduction of the seeders range and expansion of the set of seeds which can be sown with one seeder can be obtained by using a universal self-propelled small-sized base consisting of a pneumatic sowing system with replaceable mechanical sowing devices adapted to conditions of selection [1-3].

In this regard, and taking into account small size of seeders for small land plots, the use of computer technology, advanced software and three-dimensional printing will allow to produce high-tech products of any geometric shape, which can be used both for prototypes manufacturing and as finished products [4-6].

\section{Design of a grain-drill feed for a mini-seeder}

To assess feasibility of applying computer-aided design and three-dimensional printing technologies, we have analyzed different types of grain-drill feeds for metering grass seeds and developed a classification table (see Fig. 1.).

Seeds of cereals and legumes forage grasses posess a wide range of characteristics in size, density of grains and sailing capacity, therefore, due to impossibility of metering seeds with one grain-drill feed, sowing of various herbs with one seeder is not implemented up to now. These circumstances require a fleet of sowing machines for different crops, which can only be used for few hours during a year, leading to a significant increase in production costs of selection.

Taking into account the results of existing studies $[2,3,7]$ and experience in design of sowing devices, the authors of the article have chosen mechanical grain-drill feeds with a continuous metering principle of screw and disk-pin types for development of a selfpropelled pneumatic mini-seeder for sowing various herbs for selection purposes (see Fig.2.). A screw and disk-pin grain-drill feed allows high quality metering of freeflowing grass seeds in a wide size range - small and medium-seeded.

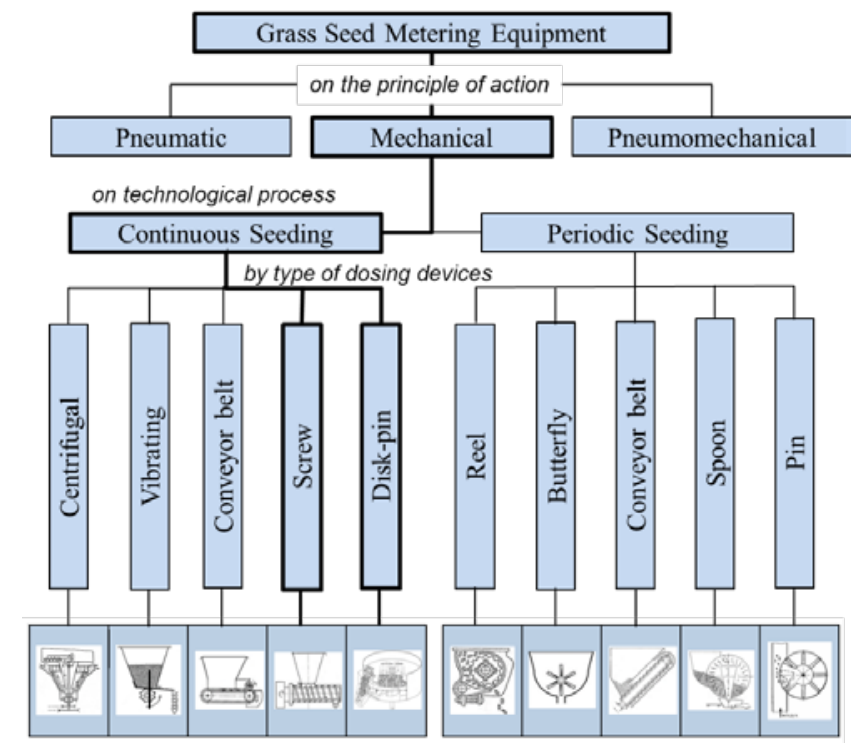

Fig. 1. Classification of grain-drill feeds for grass seed. 
The technological process of a disk-pin grain-drill feed, which uses the flow activator, allows to perform sowing of non-free-flowing, cohesive sowing materials, which have a tendency to caking and bridging. The novelty of the considered grain-drill feed is confirmed by patents for the utility model $[8,9]$.

In the design laboratory of agricultural machines of Samara State Agricultural Academy three-dimensional model of sowing devices were developed with the use of automated design system COMPASS-3D (see Fig.2, 3.).

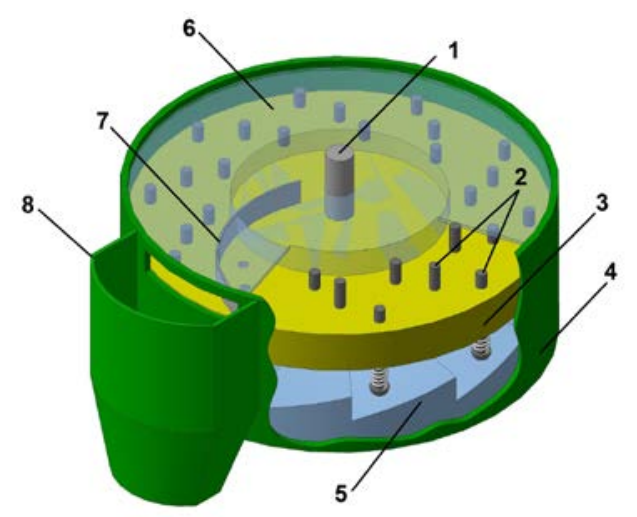

Fig. 2. 3D-model of disk-pin seeding machine: 1 - drive shaft; 2 - movable pins; 3 - seeding disc; 4 - body; 5 - step activator; 6 - visor; 7 - ejector scraper; 8 - releasing funnel.
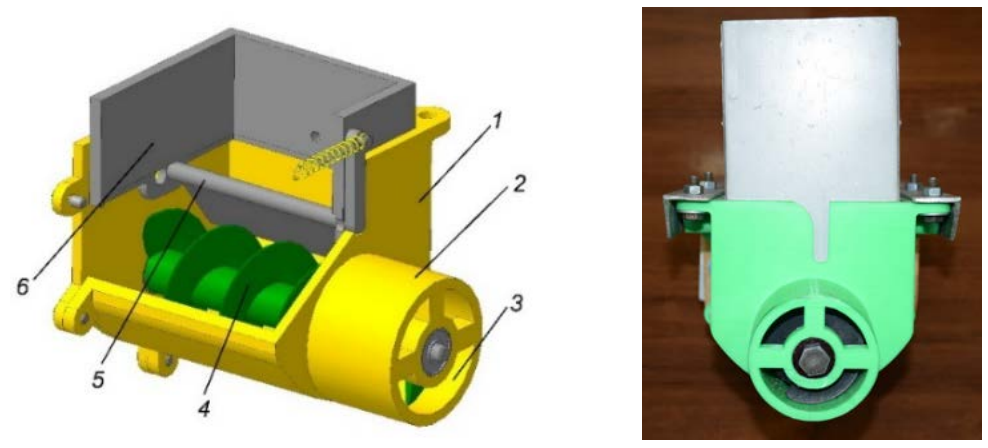

Fig. 3. (a, b) 3D Screw grain-drill feed: a - 3D - model; b - general view: 1 - body; 2 - casing; 3 releasing window; 4 - metering screw; 5 - flap; 6 - removable hopper

The use of computer-aided design with subsequent implementation of the models by manufacturing them on a 3D printer allowed the developers to work out the details of all technological features and structural elements necessary to ensure high quality of panting the seeds with different physical and mechanical properties.

\section{Study of disk-pin and screw grain-drill for grass seeds metering}

For making a valid disk-pin grain-drill feed, theoretical calculations of its performance were obtained. 
The calculated mass productivity of the grain-drill feed for a particular sowing material is determined by its design and operating parameters, that is, geometric parameters of subshield space and the speed of seeding of the sowing disc:

$$
Q_{m}=S \cdot v \cdot \gamma
$$

where: $S$ - area of the vertical section of the sub-shield space, $\mathrm{m}^{2}, v$ - speed of seeds movement by the sowing disc, $\mathrm{m} / \mathrm{s}, \gamma$ - volume mass of seeds, $\mathrm{kg} / \mathrm{m}^{3}$.

The values of the area $S$ and volume mass of seeds are known. The value of the average speed of seeds in a layer of thickness equal to the working height of the pins differs from rotation speed of the sowing disc, since the process of seeds movement determined by the friction properties of seeds and material of structural elements of the grain-drill feed.

Taking this into account and omitting the intermediate arguments, the expression for seeds metering takes the following form:

$$
Q_{m}=v_{0}\left[1-\frac{z}{l_{u m}}-\frac{2}{\pi} \sin \frac{\pi}{l_{u m}} z \cdot e^{-\frac{v \pi^{2}}{l_{u m}^{2}} t}\left(1+e^{-\frac{3 v \pi^{2}}{l_{u m}^{2}} t} \cdot \cos \frac{\pi}{l_{u m}} z\right)\right] \cdot S \cdot \gamma
$$

where: $v_{0}$ - disc speed, $\mathrm{m} / \mathrm{s}, z$ - thickness of the movable layer of seeds, $\mathrm{m}, l_{\text {um }}$ - working height of pins, $\mathrm{m}, v$ - kinematic viscosity coefficient, $\mathrm{m}^{2} / \mathrm{s}$.

During the analytical study of seed material movement by the pin disc, it was found that the average speed of seeds in the layer transported to the sub-shield space in the discharge window of the hopper is below rotation speed of the sowing disc by the value specified in the square brackets (expression 2), which in turn depends on design parameters of the grain-drill feed, physical and mechanical properties of seeds.

In figure 4, a dashed line "1" represents the values of bluegrass seeds feeding obtained analytically by the expression (2).

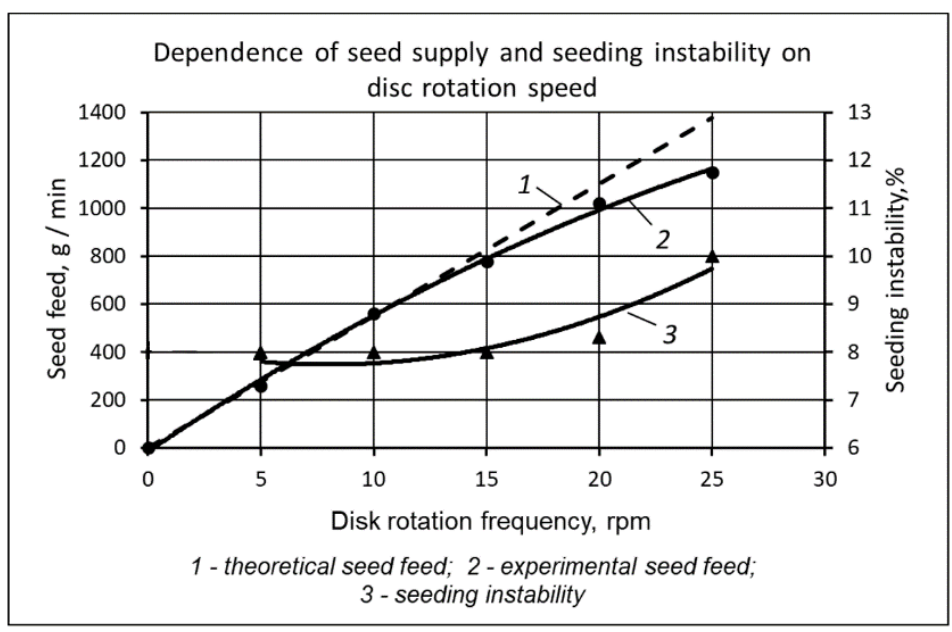

Fig. 4. Dependences of seeds supply and sowing instability on the frequency of disc rotation.

On the basis of experimental studies, we have obtained evaluation results of the influence of rotation frequency of the rotor on bluegrass seeds supply with the pin of working length of $8 \mathrm{~mm}$ and the height of actuator's steps of $8 \mathrm{~mm}$, which are presented in the form of graphic dependency "2" in figure 4. 
Due to active influence of movable pins with shaft speed of up to $15 \mathrm{rpm}$, slippage of seeds relative to the disc is virtually eliminated, thereby forming a linear dependence and high convergence of experimental results of and theoretical studies.

With installation of a grain-drill feed on a mini-seeder in field condition, the rate of bluegrass seeding instability was determined at different working speeds within a prescribed range of rotation frequencies of the grain-drill feed from 5 to $15 \mathrm{rpm}$. Values of seeding instability are presented as dependence " 3 " in figure 4 . This value does not exceed $8 \%$, which corresponds to the standards established by the agro-technical requirements for meters of non-free-flowing grass seeds.

The study of the screw grain-drill feed was carried out on sowing of small-seeded material of the mogar fodder crop with the average weight of 1000 seeds $3.1 \mathrm{~g}$.

During seeding, location of flaps in the open state over a metering screw of the graindrill feed at an angle greater than the angle of repose, provides movement of seeds at the bottom of the reception chamber and eliminates the effect of seeds level in the hopper on accuracy of seed metering by the screw.

Changing the angle of inclination of the flaps affects the process of filling the screw housing with seeds, and, consequently, on the screw performance and seeding stability.

In the process of experiments, the values of flaps angles relative to horizontal level of lower edges of the hopper were equal to: 15, 20, 25, 30, 35, and 40 degrees. The screw speed was set to a fixed $20 \mathrm{rpm}$.

According to the obtained results, graphical dependences of flaps inclination angles on screw performance and seeding instability were constructed (see Fig. 5).

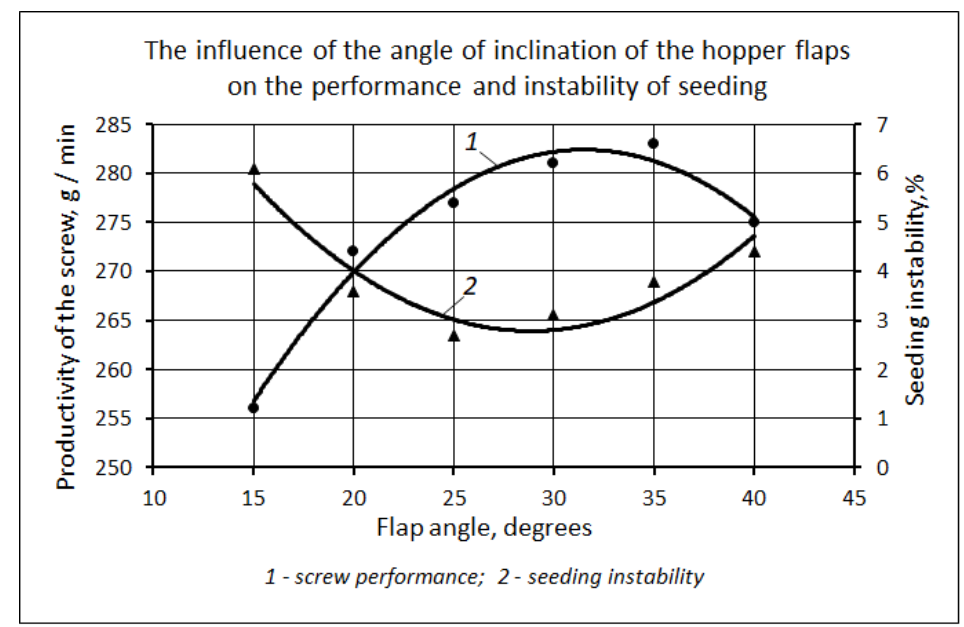

Fig. 5. Dependences of flaps inclination angles on screw performance and seeding instability.

Analysis of obtained dependences and observation results of the screw grain-drill feed operation allow us to draw the following conclusions.

At small inclination angles of flaps up to $15 . .20$ degrees, screw performance was within $250 \ldots 272 \mathrm{~g} /$ minute (dependence "1"). In addition, this value is due to small gaps between the longitudinal edges of flaps and walls of the body, which is why the flow of seeds to the bottom of the screw casing was unstable, and at an angle of less than 15 degrees has almost stopped due to bridging of seeds. The highest performance of the screw is obtained at the angles of flaps inclination of $30 \ldots 35$ degrees, the process of moving the seed to the bottom of the receiving chamber was continuous, which was confirmed by a low indicator of seeding instability (dependence "2"). The difference in 
seeds weight in experimental replicates does not exceed 2,5...3,5\%, which explains absence of effect of seed level in the hopper on precision of metering by the screw. By increasing in the angle of flap inclination to over $33 \ldots 35$ degrees, there is a decrease in screw productivity, which is explained by a decrease in filling of a screw with seeds, due to formation at the bottom of the casing of a the seeds volume with an angle of natural slope corresponding to the seeds of mogar.

\section{Results and discussion}

As a result of the research, the existing high-tech designs of a grain-drill feed with a continuous metering principle of screw and disk-pin types are designed and manufactured. Grain-drill feeds allow sowing free-flowing and non-free-flowing seeds, when used as seed meters on a self-propelled pneumatic mini-seeder for sowing grasses in selection process.

Analysis of laboratory results of and field studies of the proposed grain-drill feeds allowed to determine the qualitative indicators of their performance: at a disk rotation speed of up to $15 \mathrm{rpm}$ a linear dependence of the seed supply on the rotation frequency is provided; in the field studies, the instability of bluegrass seeding did not exceed $8 \%$. The highest performance of the screw is obtained at the angle of choke inclination of $30 \ldots .35$ degrees with the seeding instability indicator of $2.5 \ldots .3 .5 \%$.

The article was prepared within the framework of participation of A.N. Kryuchin in the competition of 2019 for the right to receive the grant of the President of the Russian Federation for state support of young Russian scientists - candidates of sciences (MK-2019).

\section{References}

1. H. Beloev, B. Borisov, V. Adamchuk, I. Petrychenko. 7th International Scientific Symposium on Farm machinery and Processes Management in Sustainable Agriculture. Gembloux, BELGIUM, NOV 25-27, 2015. Agriculture and Agricultural Science Procedia. 7. 21-26 (2015)

2. O. Pandia, I. Saracin, I. Bozga, Ş. E. Tanasie. International Conference "Agriculture for Life, Life for Agriculture". Agriculture and Agricultural Science Procedia: 6. 690-695 (2015)

3. X. Hongmei; L. Qingrong, L. Zhiweil. Advanced Materials Research. 317-319. 627-632 (2011)

4. K. Nemtinov, A. Eruslanov, Y. Nemtinova. MATEC Web of Conferences. International Conference on Modern Trends in Manufacturing Technologies and Equipment, ICMTMTE 2018; 2018. 224. 02036. (2018)

5. Three-dimensional printing or «additive manufacturing» [Electronic resource]. - URL: http:// http://3dtoday.ru/wiki/3D_print technology/]

6. L. Qiang, K. Ibrahim,Z. David 83. 10.1016/j.cor.2017.01.013. (2017).

7. Yu.M. Isaev, N.P. Kryuchin, N.M. Semashkin, A.N. Kryuchin. International Journal of Mechanical Engineering \& Technology. 9(5) 834-840 (2018)

8. Yu.A. Saveliev, N.P. Kryuchin, D.N. Kotov, A.N. Kryuchin. Pat No. 133677, Russian Federation, IPC A01C 7/00. Sowing apparatus. - \# 2013121148/13; declared 05/07/2013; publ. 10/27/2013, Bull. №30.

9. N.P. Kryuchin, O.N. Serobaba, D.N. Kotov, A.N. Kryuchin Pat. №181167, Russian Federation, IPC A01C 7/00. Screw sowing apparatus. - №2018106609, declared 02/21/2018; publ. 07/05/2018 Bull. №19 